\title{
Chronic Myelogenous Leukemia
}

\author{
Treatment and Monitoring
}

\author{
Nikolas von Bubnoff, Justus Duyster
}

\begin{abstract}
SUMMARY
Background: The treatment options for bcr-abl positive chronic myelogenous leukemia (CML) include chemotherapy, immune therapy, allogeneic stem cell transplantation, and molecular therapy. The tyrosine kinase inhibitor imatinib was approved for the treatment of CML in 2002. Data from clinical trials allow a comparison of treatment options.
\end{abstract}

Methods: The literature on the treatment and monitoring of CML was selectively reviewed. A total of 94 original articles were analyzed, along with the recommendations of an international expert committee and the medical societies. This review is current as of November 2009.

Results: In a clinical phase 3 trial of imatinib treatment for patients in the chronic phase of CML, the rates of progression-free and overall survival at 6 years were $93 \%$ and $88 \%$, respectively. Thus, imatinib is clearly superior to interferon-alpha, hydroxyurea, and busulfan with respect to survival. Allogeneic stem-cell transplantation is only a fall back option because of transplantation-associated mortality. One in four patients in the chronic phase of CML has an inadequate cytogenetic response to imatinib and therefore requires a change of treatment. Most imatinibresistant patients in the chronic phase of CML go into remission again after switching to one of the new tyrosine kinase inhibitors, dasatinib and nilotinib.

Conclusion: Imatinib is now the standard initial first-line treatment for CML in the chronic phase. Regular hematologic and cytogenetic monitoring during treatment is indispensable so that patients with an inadequate response can be identified.
Gite this as: Dtsch Arztebl Int 2010; 107(7): 114-21 DOL: 10.3238/arztebl.2010.0114

III. Medizinische Klinik und Poliklinik, Klinikum rechts der Isar, Technische Universität München: PD Dr. med. von Bubnoff, Univ.-Prof. Dr. med. Duyster
$\mathbf{R}$ ecommendations for the management of chronic myelogenous leukemia (CML) have been developed by an international team of experts $(1,2)$. These recommendations are the basis for treatment recommendations and guidelines (3, 4). Imatinib was approved for the treatment of bcr-abl-positive CML in 2002 and is currently regarded as the standard initial treatment for chronic-phase patients. The recommendations for the treatment and monitoring of CML are often not observed in practice. This means that for many patients the chance of long-lasting remission is irretrievably lost. Two other abl kinase inhibitors, dasatinib and nilotinib, have also been approved for the treatment of imatinib resistant or intolerant CML. This makes CML management more complex. The aim of this overview is to provide an aid to CML management on the basis of existing recommendations and in the light of current trial results. For this purpose, the authors carried out a selective search of the literature, including publications which examine the following aspects:

- Clinical trials on treatment and monitoring

- Prognostic implications of response during imatinib treatment

- Clinical trials of dasatinib or nilotinib in cases of resistance or intolerance to imatinib.

In view of the major significance of imatinib for the development and clinical research of new active substances in oncology, this overview also seems suitable for providing doctors not directly involved in treating CML with a general outline of treatment options.

\section{Background information}

CML is a neoplastic disease of the hematopoietic stem cells. Its incidence is 2 per 100 000/year. The peak age for the disease is 50 to 55 (e1). The Philadelphia chromosome (e2), the product of a translocation of chromosomes 9 and 22 (e3), is characteristic of CML. The resulting fusion protein acts as an active kinase. Kinase inhibitors such as imatinib block the activity of bcr-abl (e4, e5). CML is one of the few malignant diseases triggered by a single oncogene (bcr-abl) (e6, e7). This is the reason for the excellent efficacy of molecularly targeted CML therapy. Diagnosis requires evidence of bcr-abl translocation via cytogenetics, polymerase chain reactions (PCRs) or Western blot tests. CML is usually diagnosed in the initial, chronic phase (CP), which if left untreated advances to an accelerated phase (AP) after three to five years, and finally a blast crisis 
(BC). Leukocytosis of more than $100000 / \mu \mathrm{L}$ with continuous left shift leading to myeloblasts or promyelocytes and splenomegaly are characteristic of the chronic phase. The features of the accelerated phase are as follows:

- Increased numbers of blast cells in the blood or bone marrow

- Increased or decreased platelet count

- Increased numbers of basophils in the peripheral blood or

- Other chromosome anomalies (e8).

The blast crisis, with increased blast cell numbers $(\geq 20 \%)$ in the blood or bone marrow, matches the clinical picture of acute leukemia. Monitoring of CML during therapy includes measuring bcr-abl levels in the blood and bone marrow, as well as blood counts. This is why three separate levels of response are distinguished (Figure 1, Table 1) (1, e9).

\section{Chronic-phase treatment}

During the chronic phase (CP), CML can be treated with imatinib (an abl kinase inhibitor), interferon alpha (IFN, sometimes in combination with low doses of cytarabine, a cytostatic), hydroxyurea (a cytostatic), or allogeneic stem cell transplantation. Hydroxyurea can achieve a hematological response but not a cytogenetic response (e10, e11), so nowadays hydroxyurea is used for initial or palliative cytoreduction. IFN therapy with or without cytarabine can achieve a hematological response in $70 \%$ to $80 \%$ of cases, and a complete cytogenetic response (CCyR) in 5\% to 15\% (e12-e15). In a meta-analysis, IFN showed better survival figures than hydroxyurea or busulfan (5-year survival 57\% versus $42 \%$ ) (e16). IFN with or without cytarabine was therefore used as conventional standard therapy for the chronic phase at the end of the 1990s.

Imatinib was developed as an ATP-competitive inhibitor of the tyrosine kinases PDGFR, cKit and abl (see Glossary) (e4, e5) and has been approved for the treatment of CML since 2002. In a phase II trial of imatinib $400 \mathrm{mg}$ per day in CP patients with resistance or intolerance to IFN, $96 \%$ of patients achieved a complete hematological response (CHR) and 57\% achieved CCyR (5). Progression-free survival at six years was $61 \%$, overall survival $76 \%$.

A phase III randomized trial of first-line therapy for CP of imatinib $400 \mathrm{mg}$ per day demonstrated better hematological, cytogenetic, and molecular response figures than for IFN plus cytarabine $(6,7)$. After 19 months, the CCyR rate with imatinib was $76 \%$, compared to $15 \%$ for IFN plus cytarabine (6). After six years, $63 \%$ of patients were still in CCyR and receiving the imatinib trial medication (8). In the IFN plus cytarabine treatment arm, $58 \%$ of patients had switched to the imatinib arm after 19 months, 43\% because of side effects. These were mainly fatigue, depression, muscle or joint pains, neutropenia, and thrombocytopenia (6). This high crossover rate (65\% after five years) makes it harder to compare the two arms of the trial, but comparison of the imatinib arm and the IFN plus cytarabine

\section{FIGURE 1}

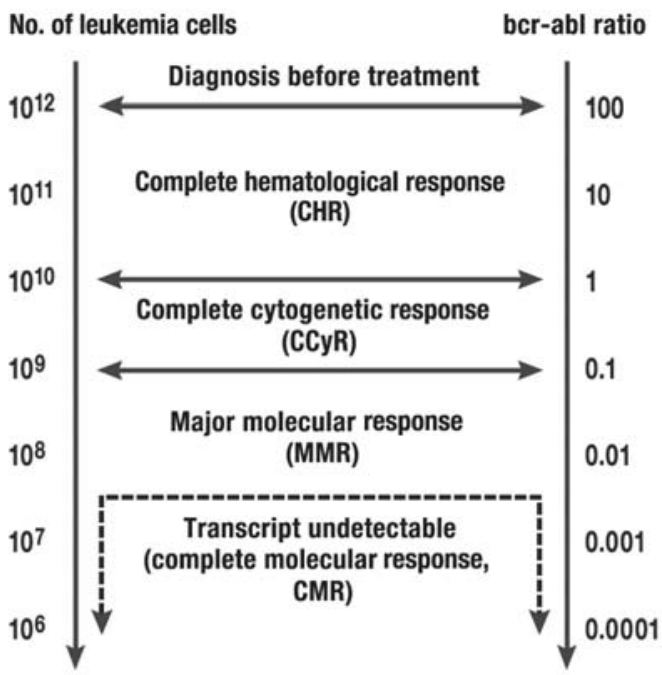

Relationship between leukemia burden, response and number of bcr-abl transcripts in the peripheral blood of CML patients (adapted according to [1] and [15]). When the disease burden decreases, the first change is that the blood count returns to normal (hematological response). Cytogenetic response documents the decrease in Philadelphia-positive metaphases in the bone marrow. Molecular response demonstrates the decrease in bcr-abl transcripts in the peripheral blood or bone marrow. After a complete cytogenetic response (CCyR) has been achieved, bcr-abl monitoring is required, using quantitative real-time PCR (qRT-PCR). Molecular response is expressed as the ratio of bcr-abl to control genes (bcr-abl ratio) or as the "log reduction" in comparison to a standard (14). CMR, complete molecular response; bcr-abl transcripts not detectable, i.e. qRT-PCR and nested PCR negative). 
TABLE 1

Definitions of response $*^{1}$

\begin{tabular}{|c|c|c|}
\hline Definition & Monitoring (CP CML, imatinib therapy) & \\
\hline $\begin{array}{l}\text { CHR } \\
\text { (complete hematological } \\
\text { response) }\end{array}$ & $\begin{array}{l}\text { - WBC }<10 \mathrm{G} / \mathrm{L} \\
\text { - Platelets }<450 \mathrm{G} / \mathrm{L} \\
\text { - No granulocyte precursors in differential blood count } \\
\text { - }<5 \% \text { basophils (all parameters are for peripheral blood) } \\
\text { - Spleen not palpable }\end{array}$ & $\begin{array}{l}\text { Every } 2 \text { weeks until CHR, } \\
\text { then every } 3 \text { months }\end{array}$ \\
\hline $\begin{array}{l}\text { Cytogenetic response } \\
\text { (bone marrow) }\end{array}$ & $\begin{array}{l}\text { - Complete (CCyR): } 0 \% \mathrm{Ph}+ \\
\text { - Partial (PCyR): } 1-35 \% \mathrm{Ph}+ \\
\text { - Minor CyR: } 36-65 \% \mathrm{Ph}+ \\
\text { - Minimal CyR: } 66-95 \% \mathrm{Ph}+ \\
\text { - No CyR: >95\% Ph+ }\end{array}$ & $\begin{array}{l}\text { Months } 3 \text { and } 6 \text {, } \\
\text { then every } 6 \text { months until CCyR } \\
\text { achieved and confirmed, } \\
\text { then every } 12 \text { months }{ }^{*^{2}}\end{array}$ \\
\hline $\begin{array}{l}\text { Molecular response } \\
\text { (qRT-PCR, peripheral blood) }\end{array}$ & $\begin{array}{l}\text { - Complete (CMR) not detectable } \\
\text { - Major (MMR) bcr-abl/control gene } \\
-\leq 0.10\end{array}$ & $\begin{array}{l}\text { Every } 3 \text { months, every } 6 \text { months } \\
\text { with CCyR + MMR }\end{array}$ \\
\hline
\end{tabular}

${ }^{*}$ Current recommendations for monitoring chronic-phase CML during imatinib therapy: modified according to the recommendations of the European Leukemia Net (ELN) (1, 2, 14-16). $\star^{2}$ After confirmed CCyR, cytogenetic monitoring is recommended every 12 months, provided regular molecular monitoring cannot be guaranteed, and should always be carried out in the event of suboptimal response or treatment failure or unexplained anaemia, leukocytopenia and/or thrombocytopenia. Ph, Philadelphia chromosome; G, giga

arm of another phase III trial shows better figures for imatinib after as little as three years: progression-free survival (PFS) of $90 \%$ versus $82 \%$, and survival of $92 \%$ versus $84 \%$ (9). These trial results established imatinib $400 \mathrm{mg}$ per day as the standard treatment for chronic-phase CML (1-4) and were also confirmed outside trials (10).

The only possible cure for CML today is allogeneic stem cell transplantation (e10, e17-e19). In the early $\mathrm{CP}$, the 5-year survival after allogeneic transplantation is between $25 \%$ and $70 \%$ (1, e20-e22). This compares to a 6 -year survival rate of $88 \%$ with imatinib (8). There are no randomized clinical trials which allow direct comparison of the two forms of therapy. Because of transplantation-associated morbidity and mortality, as well as efficacy and tolerability, the current consensus is that imatinib is the first-line therapy of choice for the chronic phase (1-4). One indication for allogeneic stem cell transplantation is resistance to imatinib treatment and newer tyrosine kinase inhibitors, or progression to the accelerated phase or blast crisis.

\section{Side effects of imatinib}

Overall, imatinib is a very well-tolerated drug. Serious side effects (Grade 3-4) mainly affect hematopoiesis and are partly caused by its anti-leukemia effect. The most common side effects are neutropenia (17\% in CP, up to $64 \%$ in BC) (11, e23, e24), thrombocytopenia (9\% in CP, up to $62 \%$ in BC) (11, e23, e24), elevated liver enzymes (5\% in CP) (11) and fluid retention
(5.8\% in BC) (e23). Other relatively common side effects (>10\% of patients) are mostly mild (Grade 1 ) or moderate (Grade 2). These include fluid retention (11\% to $60 \%$ ), nausea (50\% to $65 \%$ ), vomiting ( $17 \%$ to $49 \%$ ), abdominal pain (10\% to $37 \%)$, muscle cramps ( $25 \%$ to $49 \%$ ), musculoskeletal pains ( $12 \%$ to $47 \%$ ), fatigue ( $8 \%$ to $39 \%)$, skin rashes (22\% to $40 \%)$, diarrhea ( $24 \%$ to $45 \%$ ), and headaches (10\% to $37 \%$ ). Interestingly, these side effects tend to appear in the first two years of treatment, and side effects become significantly less frequent after this period $(6,11$, e23, e24). Termination of imatinib treatment because of side effects is rare, with figures of between $3 \%$ and $5 \%$ in clinical trials (8, e23, e24). A rare but potentially dangerous side effect is congestive heart failure, which is observed in $0.2 \%$ to $0.6 \%$ of cases (e25-e29). Current recommendations should be observed for the management of imatinib side effects $(4,12,13)$. Interactions with concomitant medication should be reviewed paying particular attention to active substances which induce or inhibit CYP4503A4/5 (4, 12, 13). Grapefruit and starfruit consumption can increase plasma concentrations of imatinib $(4,12,13)$.

\section{Monitoring during the chronic phase}

Regular monitoring is needed to ascertain promptly whether patients are responding well to treatment. Recommendations for monitoring have been developed (Tables 1 and 2) (1-4, 14-16). With first-line imatinib therapy, achieving hematological and cytogenetic responses after 3,6 , and 12 months is prognostically 
Definitions of treatment targets and treatment failure*1

\begin{tabular}{|c|c|c|c|}
\hline Time lapse & Resistance & Suboptimal response & Treatment target \\
\hline 3 months & No CHR & $\begin{array}{l}\text { No cytogenetic } \\
\text { response }(\mathrm{Ph}+>95 \%)\end{array}$ & CHR, minor CyR $(\mathrm{Ph}+\leq 65 \%)$ \\
\hline 6 months & $\begin{array}{l}\text { No cytogenetic } \\
\text { response (Ph+>95\%) }\end{array}$ & No PCyR (Ph+ >35\%) & PCyR $(\mathrm{Ph}+\leq 35 \%)$ \\
\hline 12 months & No PCyR (Ph+ >35\%) & PCyR $(\mathrm{Ph}+1 \%-35 \%)$ & CCyR (Ph+ 0\%) \\
\hline 18 months & No CCyR (Ph+ $\geq 1 \%)$ & $\begin{array}{l}\text { No MMR (i.e. bcr-abl/control gene ratio } \\
>0.10 \text { ) }\end{array}$ & MMR \\
\hline Any time & $\begin{array}{l}\text { - Loss of CHR } \\
\text { - Loss of CCyR } \\
\text { - Evidence of bcr-abl mutation } \star^{2} \\
\text { - ACA in Ph+ cells }\end{array}$ & $\begin{array}{l}\text { - Loss of MMR } \\
\text { - Evidence of bcr-abl mutation } \star^{2}\end{array}$ & \\
\hline
\end{tabular}

$*^{1}$ (Optimal response), suboptimal response and resistance (treatment failure) to imatinib treatment in chronic-phase CML modified according to the recommendations of the European Leukemia Net (ELN) (1) Definitions of hematological (CHR), cytogenetic (PCyR, CCyR) and molecular (MMR) response (Table 1). ACA: additional chromosomal abnormalities in bcr-abl-positive $(\mathrm{Ph}+)$ cells in cytogenetics. bcr-abl mutation: resistance mutation in the bcr-abl gene. Binding of the kinase inhibitor may be impaired by the resulting amino acid exchange in the protein. This may reduce efficacy. $\star^{2}$ The evidence of a mutation of the bcr-abl kinase domains with no residual sensitivity to imatinib determines therapy failure. Evidence of a mutation of the bcr-abl kinase domain with residual sensitivity to imatinib determines suboptimal response.

relevant to progression-free and overall survival $(9,11$, $17,18)$. If treatment is continued without cytogenetic response, there is a danger of the disease progressing to the accelerated phase or blast crisis. Failure to achieve CCyR after 12 months was associated with lower survival figures at 5 years (98\% versus $86 \%$ ) in one trial (18). Complete molecular response (CMR) reflects a small disease burden (Figure 1), but cannot be considered a cure. If imatinib therapy is halted during CMR, half of patients suffer molecular relapse, and also cytogenetic and hematological relapse if treatment is not resumed (e30-e35).

\section{Treatment of advanced CML}

Treatment options include imatinib, cytostatic mono- or combination therapy, and allogeneic stem cell transplantation. In patients with CML in AP or BC, response rates with imatinib in phase II trials were lower than for the CP, but still significantly better than with conventional chemotherapy (e23, e24, e36-e38). With imatinib 400-600 mg, the survival rate for AP was 53\% at 4 years and $43 \%$ after 7 years (e36, e37). For CML in $\mathrm{BC}$, survival with imatinib $600 \mathrm{mg}$ per day in a phase II trial was $11 \%$ after 3 years (e38). For advanced CML, the recommended dose of imatinib is $600 \mathrm{mg}$ per day. Allogeneic stem cell transplantation should be attempted immediately for patients in BC (1, 3, 4, e38). For patients in AP, there is a correlation between CCyR achieved with imatinib $600 \mathrm{mg}$ per day (approx. 20\% of patients [e37]) and survival for more than 5 years (e36, e37). With close monitoring, these patients should receive allogeneic transplantation if cytogenetic or hematological response is lost.

\section{Imatinib resistance: frequency}

Primary resistance to imatinib means that a hematological or cytogenetic response has not been achieved after a specific length of time (Table 2). In first-line therapy for the chronic phase, primary resistance to imatinib is associated with significantly worse survival rates (9, $11,17,18)$. Primary hematological resistance to imatinib occurs during the early CP in less than $5 \%$ of cases (6, e47). Primary cytogenetic resistance to imatinib is observed in $3 \%$ to $18 \%$ after 6 months $(24,18), 15 \%$ to $27 \%$ after 12 months $(11,18)$, and $23 \%$ to $49 \%$ after 18 months $(9,18)$. Secondary resistance is defined as the loss of previously achieved hematological or cytogenetic responses and progression to AP or BC. With imatinib first-line therapy for the chronic phase in a phase III trial, the yearly rate for secondary resistance and death from the second year (7.5\%) to the sixth year $(0.4 \%)$ fell steadily (8). In advanced CML, primary hematological resistance to imatinib is significantly more common, affecting $18 \%$ to $30 \%$ of patients in AP and $60 \%$ of patients in BC. At four years the resistance rates are $45 \%$ to $70 \%$ (AP) and $90 \%$ (BC) of cases (e36, e37, e39-e42).

\section{Imatinib resistance: causes}

One common cause of insufficient response is poor adherence to treatment (e43). Interruptions to treatment and dose reductions must be avoided. When there is 


\author{
Customized \\ treatment plan: \\ proposed action in \\ the event of clinical \\ resistance to imati- \\ nib in CML patients \\ $(1-4,18)$. Mutation \\ analysis of the bcr- \\ abl gene serves as \\ evidence of mu- \\ tations which may \\ cause resistance to \\ imatinib, dasatinib \\ and/or nilotinib (14)
}

\section{FIGURE 2}

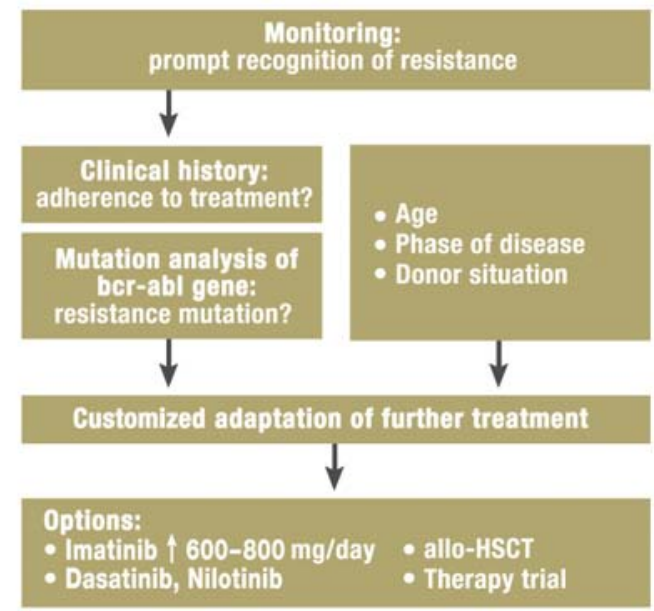

resistance, there are often mutations of the bcr-abl kinase domain (e44-e49). These affect the binding of imatinib. There may also be additional cytogenetic abnormalities (e46, e50, e51) or an amplification of the bcr-abl gene (e44, e52). Differences in pharmacokinetics may promote resistance (e53-e55). Different resistance mechanisms may coexist and interact with each other (e56-e58).

\section{Action to take in the event of suboptimal response or resistance}

If there is suboptimal response or resistance to imatinib in CP after 3, 6, or 12 months (Table 2), progressionfree and overall survival rates are significantly lower $(9,11,17,18)$. This means the treatment must be changed. Increasing the dose to $600-800 \mathrm{mg}$ can improve the quality of response (e59-e63). If increasing the dose has no effect, the patient should be switched to another approved abl kinase inhibitor (dasatinib, nilotinib) (2-4). Mutation analysis of the bcr-abl gene should be carried out if there is resistance or a reproducible increase in bcr-abl transcripts (1-4, 14, e64). Patients with a strongly imatinib-resistant mutation do not generally benefit from a higher dose of imatinib (e63). In such cases patients should be switched to nilotinib or dasatinib, provided these have an effect on the mutation (2-4, e65). In patients with T315I mutation, none of the approved kinase inhibitors is effective (e44, e66, e67). The options available in such cases are allogeneic stem cell transplantation or participation in a therapy trial (Figure 2) $(1,4,9,18)$. Substances which are active against bcr-abl/T315I are currently being tested in clinical trials. In the event of progression to AP or BC, dasatinib or nilotinib generally achieve only a short-term response, and allogeneic stem cell transplantation should therefore be attempted (4, 19, e68, e69).

\section{Clinical results with approved 2nd-generation tyrosine kinase inhibitors}

Dasatinib has been approved for the treatment of all phases of CML and Philadelphia chromosome-positive acute lymphoblastic leukemia ( $\mathrm{Ph}+\mathrm{ALL})$, in cases which are resistant or intolerant to imatinib. Nilotinib has been approved for patients with CML in CP or AP who are intolerant or resistant to imatinib. Both substances, like imatinib, act as ATP competitors. Phase II trials successfully recorded clinical activity in imatinibresistant CML for both substances (20-25, e70-e72).

\section{Dasatinib: chronic phase}

In a phase II trial involving $\mathrm{CP}$ with resistance or intolerance to imatinib, hematological and cytogenetic responses were successfully achieved using dasatinib at a dose of 2 x $70 \mathrm{mg}$ (at 15 months: CHR 91\%; CCyR $40 \%$ with resistance, $75 \%$ with intolerance) (20). At 15 months the overall survival rate was 96\%, and progression-free survival (PFS) $90 \%$. The rate of Grade 3-4 neutropenia was 49\%, and Grade 3-4 thrombocytopenia $48 \%$. The main non-hematological Grade 3-4 toxicities were dyspnea (5\%) and pleural effusions (6\%). In a randomized phase II trial, dasatinib 2 x $70 \mathrm{mg}$ proved more effective than imatinib $2 \mathrm{x}$ $400 \mathrm{mg}$ in chronic-phase CML with resistance to imatinib $400 \mathrm{mg}$ (PFS at two years: 86\% versus 65\%) (e72). A phase III trial showed comparable efficacy and better tolerance for a dose of $1 \times 100 \mathrm{mg}$ (24). This dose is therefore recommended for the treatment of chronicphase CML with resistance or intolerance to imatinib.

\section{Dasatinib: advanced CML}

A phase II trial involving dasatinib $2 \times 70 \mathrm{mg}$ in patients with accelerated-phase CML and resistance or intolerance to imatinib yielded CHR and CCyR rates of $45 \%$ and $32 \%$ respectively at 14 months (21). Overall survival at one year was $82 \%$, and PFS $66 \%$. In a phase III trial, dasatinib 1 x $140 \mathrm{mg}$ showed significantly fewer pleural effusions than $2 \times 70 \mathrm{mg}$, with the same efficacy. This former dose is therefore recommended for patients with accelerated-phase CML and resistance or intolerance to imatinib (e73). In the event of BC and resistance or intolerance to imatinib, hematological and cytogenetic responses were demonstrated with dasatinib (22). However, PFS was less than 6 months, and overall survival less than one year. The recommended dose in such cases is $2 \times 70 \mathrm{mg}$ per day.

\section{Nilotinib: chronic phase}

In chronic-phase CML patients with resistance or intolerance to imatinib, a phase II trial involving nilotinib 2 x $400 \mathrm{mg}$ achieved hematological and cytogenetic responses (at 6 months, CHR was 74\%; CCyR 30\% for resistance and $35 \%$ for intolerance) (23). The PFS rate at 12 months was $78 \%$, and the overall survival rate was $95 \%$. 29\% of patients suffered Grade 3-4 neutropenia and thrombocytopenia. Grade 3-4 nonhematological toxicities included increased bilirubin (8\%), blood glucose (13\%), and lipase (15\%) levels. 


\section{Nilotinib: advanced CML}

In the AP with resistance or intolerance to imatinib, a phase II trial involving nilotinib 2 x $400 \mathrm{mg}$ achieved CHR in 26\% of patients after 6 months, and CCyR in $16 \%$ (25). After 12 months the PFS rate was 57\% and the overall survival rate was $79 \%$. In patients with BC and resistance or intolerance to imatinib, hematological and cytogenetic responses were observed in some patients in a phase II trial involving treatment with nilotinib 2 x 400 mg (Giles F, Larson R, Kantarjian H et al.: Nilotinib in patients [pts] with Philadelphia chromosome-positive $(\mathrm{Ph}+)$ chronic myelogenous leukemia in blast crisis [CML-BC] who are resistant or intolerant to Imatinib. 49th ASH Annual Meeting, 2007, Atlanta. Blood; 110: 310A). The overall survival rate in this trial at 12 months was $42 \%$.

\section{Treatment}

There are still open questions regarding chronic myelogenous leukemia.

- The prognostic significance of 'suboptimal response' and 'resistance' or long term 'treatment failure' during imatinib therapy are currently being examined in trials. This will affect future recommendations and guidelines for the treatment and monitoring of chronic-phase chronic myelogenous leukemia.

- Can the results of imatinib in first-line therapy for chronic-phase CML be further improved? Planned and ongoing phase III trials compare imatinib $400 \mathrm{mg}$ per day with imatinib plus interferon alpha, imatinib $800 \mathrm{mg}$ per day and the alternative tyrosine kinase inhibitors dasatinib, nilotinib, and bosutinib.

- Could imatinib be curative in some patients? Ongoing trials are investigating whether stopping imatinib therapy in chronic-phase patients with a stable, complete molecular response leads to relapse in all patients. However, controlled discontinuation of imatinib should only take place within clinical trials.

- It is not yet known whether lasting remission can be achieved in imatinib-resistant CML with the approved second-line substances dasatinib and nilotinib.

Information (in German) on ongoing trials can be found on the official website, Akute und Chronische Leukämien ('Acute and Chronic Leukemias'): http://www.kompetenznetz-leukaemie.de/content/home.

\section{Monitoring chronic-phase CML: criteria for defining relapse during treatment}

For criteria for defining hematological, cytogenetic and molecular response, see also Tables 1 and 2.

- Hematological relapse: loss of CHR (differential blood count, size of spleen); corresponds to treatment failure or imatinib resistance

- Cytogenetic relapse: loss of CCyR (evidence of $\mathrm{Ph}+$ metaphases in bone marrow); corresponds to treatment failure or imatinib resistance

\section{GLOSSARY}

abl: $\quad$ Abelson kinase (chromosome 9), part of Philadelphia translocation $\mathrm{t}(9 ; 22)$ and therapy target structure for the tyrosine kinase inhibitors imatinib, nilotinib and dasatinib

AP: $\quad$ Accelerated phase of CML

BC: $\quad$ Blast crisis of $\mathrm{CML}$

bcr-abl: Gene or protein product of Philadelphia translocation $\mathrm{t}(9 ; 22)$

CCyR: Complete cytogenetic response (see Table 1 for definition)

CHR: Complete hematological response (see Table 1 for definition)

CML: Chronic myelogenous leukemia

CMR: Complete molecular response (see Table 1 for definition)

CP: $\quad$ Chronic phase of CML

IFN: Interferon alpha

MCyR: Major cytogenetic response (see Table 1 for definition)

MMR: Major molecular response (see Table 1 for definition)

PCyR: Partial cytogenetic response (see Table 1 for definition)

PDGFR: Platelet-derived growth factor receptor

PFS: Progression-free survival (no progression in $A P / B C$ )

Ph+ ALL: Philadelphia chromosome-positive acute lymphatic leukemia

qRT-PCR: Quantitative real-time polymerase chain reaction 
- The standard treatment for chronic-phase CML is long-term imatinib therapy at a dose of $400 \mathrm{mg}$ per day. Interruptions to treatment and dose reductions must be avoided. The aim of treatment is lasting complete cytogenetic response.

- Regular monitoring of disease activity is essential, to identify patients with insufficient response to imatinib (suboptimal response/resistance).

- Insufficient response to imatinib is associated with lower progression-free and overall survival rates. Unless changes are made to treatment, there is a risk of the disease advancing to the accelerated phase or blast crisis.

- If there is insufficient response to imatinib, the patient should be referred to a specialist center. The possible options are a higher dose of imatinib, nilotinib, dasatinib, allogeneic transplantation and participation in a therapy trial, depending on the resistance mechanism, age, disease phase, and donor situation.

- Dasatinib and nilotinib are abl kinase inhibitors which have been approved as second-line therapy. Clinical trials show good efficacy and tolerability of both substances in CML patients with resistance or intolerance to imatinib.

- Molecular relapse: loss of MMR (increase in bcr-abl/control gene ratio $>0.10$ in qRT-PCR in the peripheral blood); corresponds to suboptimal response to imatinib.

When there is increased disease activity during treatment, the next stage is generally loss of molecular response, followed by loss of cytogenetic and eventually also hematological response (Figure 1).

\section{Conflict of interest statement}

Both authors are members of the Novartis Advisory Board.

Manuscript submitted 6 March 2009, revised version accepted 7 August 2009.

Translated from the original German by Caroline Devitt, MA.

\section{REFERENCES}

1. Baccarani M, Saglio G, Goldman J, et al.: Evolving concepts in the management of chronic myeloid leukemia. Recommendations from an expert panel on behalf of the European Leukemia Net. Blood 2006; 108: 1809-20.

2. Baccarani M, Cortes J, Pane F, et al.: Chronic myeloid leukemia: an update of concepts and management recommendations of European Leukemia Net. J Clin Oncol 2009; 27(35): 6041-51.

3. Hochhaus A, Brümmendorf T, Le Coutre P: Empfehlungen der DGHO für die Diagnostik und Therapie hämatologischer und onkologischer Erkrankungen. Chronische Myeloische Leukämie. http://www.dgho. de/onkopedia

4. National Comprehensive Cancer Network: NCCN Clinical Practice Guidelines in Oncology. Chronic Myelogenous Leukemia. www. nccn.org

5. Hochhaus A, Druker B, Sawyers C, et al.: Favorable long-term follow-up results over 6 years for response, survival, and safety with imatinib mesylate therapy in chronic-phase chronic myeloid leukemia after failure of interferon-alpha treatment. Blood 2008 111: 1039-43

6. O'Brien SG, Guilhot F, Larson RA, et al.: Imatinib compared with interferon and low-dose cytarabine for newly diagnosed chronic-phase chronic myeloid leukemia. N Engl J Med 2003; 348: 994-1004.

7. Hughes TP, Kaeda J, Branford S, et al.: Frequency of major molecular responses to imatinib or interferon alfa plus cytarabine in newly diagnosed chronic myeloid leukemia. N Engl J Med 2003; 349: 1423-32.

8. Hochhaus A, O'Brien SG, Guilhot F, et al.: Six-year follow-up of patients receiving imatinib for the first-line treatment of chronic myeloid leukemia. Leukemia 2009; 23: 1054-61.

9. Roy L, Guilhot J, Krahnke T, et al.: Survival advantage from imatinib compared with the combination interferon-alpha plus cytarabine in chronic-phase chronic myelogenous leukemia: historical comparison between two phase 3 trials. Blood 2006; 108: 1478-84.

10. de Lavallade H, Apperley JF, Khorashad JS, et al.: Imatinib for newly diagnosed patients with chronic myeloid leukemia: incidence of sustained responses in an intention-to-treat analysis. J Clin Oncol 2008; 26: 3358-63.

11. Druker BJ, Guilhot F, O'Brien SG, et al.: Five-year follow-up of patients receiving imatinib for chronic myeloid leukemia. N Engl J Med 2006; 355: 2408-17

12. Deininger MW, O'Brien SG, Ford JM, Druker BJ: Practical management of patients with chronic myeloid leukemia receiving imatinib. J Clin Oncol 2003; 21: 1637-47.

13. Quintas-Cardama A, Cortes JE, Kantarjian H: Practical management of toxicities associated with tyrosine kinase inhibitors in chronic myeloid leukemia. Clin Lymphoma Myeloma 2008; 8 Suppl 3: p. 82-8.

14. Hughes T, Deininger M, Hochhaus A, et al.: Monitoring CML patients responding to treatment with tyrosine kinase inhibitors: review and recommendations for harmonizing current methodology for detecting BCR-ABL transcripts and kinase domain mutations and for expressing results. Blood 2006; 108: 28-37.

15. Goldman JM: How I treat chronic myeloid leukemia in the imatinib era. Blood 2007; 110: 2828-37.

16. Kantarijan H, Schiffer C, Jones D, Cortes J: Monitoring the response and course of chronic myeloid leukemia in the modern era of BCR$\mathrm{ABL}$ tyrosine kinase inhibitors: practical advice on the use and interpretation of monitoring methods. Blood 2008; 111: 1774-80.

17. Kantarian H, O'Brien S, Shan J, et al.: Cytogenetic and molecula responses and outcome in chronic myelogenous leukemia: need for new response definitions? Cancer 2008; 112: 837-45.

18. Marin D, Milojkovic D, Olavarria E, et al.: European LeukemiaNet criteria for failure or suboptimal response reliably identify patients with $\mathrm{CML}$ in early chronic phase treated with imatinib whose eventual outcome is poor. Blood 2008; 112: 4437-44.

19. Cortes J, Rousselot P, Kim DW, et al.: Dasatinib induces complete hematologic and cytogenetic responses in patients with imatinibresistant or -intolerant chronic myeloid leukemia in blast crisis. Blood 2007; 109: 3207-13.

20. Hochhaus A, Baccarani M, Deininger $M$, et al.: Dasatinib induces durable cytogenetic responses in patients with chronic myelogenous leukemia in chronic phase with resistance or intolerance to imatinib. Leukemia 2008; 22: 1200-6.

21. Apperley JF, Cortes JE, Kim DW, et al.: Dasatinib in the treatment of chronic myeloid leukemia in accelerated phase after imatinib failure: the START a trial. J Clin Oncol 2009; 27: 3472-9. 
22. Cortes J, Kim DW, Raffoux E, et al.: Efficacy and safety of dasatinib in imatinib-resistant or -intolerant patients with chronic myeloid leukemia in blast phase. Leukemia 2008; 22: 2176-83.

23. Kantarijian $\mathrm{HM}$, Giles $\mathrm{F}$, Gattermann $\mathrm{N}$, et al.: Nilotinib (formerly AMN107), a highly selective BCR-ABL tyrosine kinase inhibitor, is effective in patients with Philadelphia chromosome-positive chronic myelogenous leukemia in chronic phase following imatinib resistance and intolerance. Blood 2007; 110: 3540-6.

24. Shah NP, Kantarjian HM, Kim DW, et al.: Intermittent target inhibition with dasatinib $100 \mathrm{mg}$ once daily preserves efficacy and improves tolerability in imatinib-resistant and -intolerant chronic-phase chronic myeloid leukemia. J Clin Oncol 2008; 26: 3204-12.

25. le Coutre P, Ottmann OG, Giles F, et al.: Nilotinib (formerly AMN107), a highly selective BCR-ABL tyrosine kinase inhibitor, is active in patients with imatinib-resistant or -intolerant accelerated phase chronic myelogenous leukemia. Blood 2008; 111: 1834-9.

Corresponding author

PD Dr. med. Nikolas von Bubnoff

III. Medizinische Klinik und Poliklinik

Klinikum rechts der Isar

Technische Universität München

Ismaningerstr. 22

81675 München, Germany

n.bubnoff@Irz.tum.de

For e-references please refer to:

www.aerzteblatt-international.de/ref0710 


\title{
Chronic Myelogenous Leukaemia
}

\author{
Treatment and Monitoring
}

Nikolas von Bubnoff, Justus Duyster

\section{E-References}

e1. Goldman JM, Melo JV: Chronic myeloid leukemia—advances in biology and new approaches to treatment. N Engl J Med 2003; 349: 1451-64.

e2. Nowell PC, Hungerford D: A minute chromosome in human granulocytic leukaemia. Science 1960; 132: 1497-501.

e3. Rowley JD: Letter: A new consistent chromosomal abnormality in chronic myelogenous leukaemia identified by quinacrine fluorescence and Giemsa staining. Nature 1973; 243: 290-93.

e4. Zimmermann J, Buchdunger E, Mett H, Meyer T, Lydon N, Traxler P: (Phenylamino)pyrimidine (PAP) derivatives: a new class of potent and highly selective PDGF-receptor autophosphorylation inhibitors. Bioorg Med Chem Lett 1996; 6: 1221-26.

e5. Druker BJ, Tamura S, Buchdunger E, et al.: Effects of a selective inhibitor of the Abl tyrosine kinase on the growth of Bcr-Abl positive cells. Nat.Med. 1996; 2: 561-66.

e6. Daley GQ, Van Etten RA, Baltimore D: Induction of chronic myelogenous leukemia in mice by the P210bcr/abl gene of the Philadelphia chromosome. Science 1990; 247: 824-30.

e7. Lugo TG, Pendergast AM, Muller AJ, Witte ON: Tyrosine kinase activity and transformation potency of bcr-abl oncogene products. Science 1990; 247: 1079-82.

e8. Kantarjian HM, Dixon D, Keating MJ, et al.: Characteristics of accelerated disease in chronic myelogenous leukemia. Cancer 1988; 61: 1441-6.

e9. Talpaz M, Kantarijan HM, McCredie K, Trujillo JM, Keating MJ, Gutterman JU: Hematologic remission and cytogenetic improvement induced by recombinant human interferon alpha $\mathrm{A}$ in chronic myelogenous leukemia. N Engl J Med 1986; 314: 1065-9.

e10. Italian Cooperative Study Group on Chronic Myeloid Leukemia and Italian Group for Bone Marrow Transplantation. Monitoring treatment and survival in chronic myeloid leukemia. J Clin Oncol 1999; 17: 1858-68.

e11. Hehlmann R, Berger U, Pfirrmann M, et al.: Randomized comparison of interferon alpha and hydroxyurea with hydroxyurea monotherapy in chronic myeloid leukemia (CML-study II): prolongation of survival by the combination of interferon alpha and hydroxyurea. Leukemia 2003; 17: 1529-37.

e12. Hehlmann R, Heimpel H, Hasford J, et al.: Randomized comparison of interferon-alpha with busulfan and hydroxyurea in chronic myelogenous leukemia. The German CML Study Group. Blood 1994; 84: 4064-77.

e13. Guilhot F, Chastang C, Michallet M, et al.: Interferon alfa-2b combined with cytarabine versus interferon alone in chronic myelogenous leukemia. French Chronic Myeloid Leukemia Study Group. N Engl J Med 1997; 337: 223-29.

e14. Baccarani M, Rosti G, de Vivo A, et al.: A randomized study of interferon-alpha versus interferon-alpha and low-dose arabinosyl cytosine in chronic myeloid leukemia. Blood 2002; 99: 1527-35.

e15. Bonifazi F, de Vivo A, Rosti G, et al.: Chronic myeloid leukemia and interferon-alpha: a study of complete cytogenetic responders. Blood 2001; 98: 3074-81. e16. Interferon alfa versus chemotherapy for chronic myeloid leukemia: a meta-analysis of seven randomized trials: Chronic Myeloid Leukemia Trialists' Collaborative Group. J Natl Cancer Inst 1997; 89: 1616-20.

e17. Simonsson B, Oberg G, Bjoreman M, et al.: Intensive treatment and stem cell transplantation in chronic myelogenous leukemia: long-term follow-up. Acta Haematol 2005; 113: 155-62.

e18. Robin M, Guardiola P, Devergie A, et al.: A 10-year median followup study after allogeneic stem cell transplantation for chronic myeloid leukemia in chronic phase from HLA-identical sibling donors. Leukemia 2005; 19: 1613-20.

e19. Socie G, Clift RA, Blaise D, et al.: Busulfan plus cyclophosphamide compared with total-body irradiation plus cyclophosphamide before marrow transplantation for myeloid leukemia: long-term follow-up of 4 randomized studies. Blood 2001; 98: 3569-74.

e20. Gratwohl A, Hermans J, Goldman JM, et al.: Risk assessment for patients with chronic myeloid leukaemia before allogeneic blood or marrow transplantation. Chronic Leukemia Working Party of the European Group for Blood and Marrow Transplantation. Lancet 1998; 352: 1087-92.

e21. Passweg JR, Walker I, Sobocinski KA, Klein JP, Horowitz MM, Giralt SA: Validation and extension of the EBMT Risk Score for patients with chronic myeloid leukaemia (CML) receiving allogeneic haematopoietic stem cell transplants. Br J Haematol 2004; 125: 613-20.

e22. De Souza CA, Vigorito AC, Ruiz MA, et al.: Validation of the EBMT risk score in chronic myeloid leukemia in Brazil and allogeneic transplant outcome. Haematologica 2005; 90: 232-7.

e23. Sawyers CL, Hochhaus A, Feldman E, et al.: Imatinib induces hematologic and cytogenetic responses in patients with chronic myelogenous leukemia in myeloid blast crisis: results of a phase II study. Blood 2002; 99: 3530-39.

e24. Talpaz M, Silver RT, Druker BJ, et al.: Imatinib induces durable hematologic and cytogenetic responses in patients with accelerated phase chronic myeloid leukemia: results of a phase 2 study. Blood 2002; 99: 1928-37.

e25. Verweij J, Casali PG, Kotasek D, et al.: Imatinib does not induce cardiac left ventricular failure in gastrointestinal stromal tumour patients: analysis of EORTC-ISG-AGITG study 62005. Eur J Cancer 2007; 43: 974-8.

e26. Atallah E, Durand JB, Kantarjian H, Cortes J: Congestive heart failure is a rare event in patients receiving imatinib therapy. Blood 2007; 110: 1233-7.

e27. Hatfield A, Owen S, Pilot PR: In reply to 'Cardiotoxicity of the cancer therapeutic agent imatinib mesylate'. Nat Med 2007; 13: 13; author reply 15-6.

e28. Gambacorti-Passerini C, Tornaghi L, Franceschino A, Piazza R, Corneo G, Pogliani E: In reply to 'Cardiotoxicity of the cancer therapeutic agent imatinib mesylate'. Nat Med 2007; 13: 13-4; author reply 15-6.

e29. Rosti G, Martinelli G, Baccarani M: In reply to 'Cardiotoxicity of the cancer therapeutic agent imatinib mesylate'. Nat Med 2007; 13: 15; author reply 15-6. 
e30. Mauro MJ, Druker BJ, Maziarz RT: Divergent clinical outcome in two CML patients who discontinued imatinib therapy after achieving a molecular remission. Leuk Res 2004; 28 Suppl 1: S71-3.

e31. Cortes J, O'Brien S, Kantarjian H: Discontinuation of imatinib therapy after achieving a molecular response. Blood 2004; 104: 2204-5.

e32. Hess G, Bunjes D, Siegert W, et al.: Sustained complete molecular remissions after treatment with imatinib-mesylate in patients with failure after allogeneic stem cell transplantation for chronic myelogenous leukemia: results of a prospective phase II open-label multicenter study. J Clin Oncol 2005; 23: 7583-93.

e33. Merante S, Orlandi E, Bernasconi P, Calatroni S, Boni M, Lazzarino M: Outcome of four patients with chronic myeloid leukemia after imatinib mesylate discontinuation. Haematologica 2005; 90: 979-81.

e34. Breccia M, Diverio D, Pane F, et al.: Discontinuation of imatinib therapy after achievement of complete molecular response in a $\mathrm{Ph}(+) \mathrm{CML}$ patient treated while in long lasting complete cytogenetic remission (CCR) induced by interferon. Leuk Res 2006; 30: 1577-9.

e35. Rousselot P, Huguet F, Rea D, et al.: Imatinib mesylate discontinuation in patients with chronic myelogenous leukemia in complete molecular remission for more than 2 years. Blood 2007; 109: 58-60.

e36. Kantarjian H, Talpaz M, O'Brien S, et al.: Survival benefit with imatinib mesylate therapy in patients with accelerated-phase chronic myelogenous leukemia - comparison with historic experience. Cancer 2005; 103: 2099-108.

e37. Palandri F, Castagnetti F, Alimena G, et al.: The long-term durability of cytogenetic responses in patients with accelerated phase chronic myeloid leukemia treated with imatinib $600 \mathrm{mg}$ : the GIMEMA CML Working Party experience after a 7-year follow-up. Haematologica 2009; 94: 205-12.

e38. Palandri F, Castagnetti F, Testoni N, et al.: Chronic myeloid leukemia in blast crisis treated with imatinib $600 \mathrm{mg}$ : outcome of the patients alive after a 6-year follow-up. Haematologica 2008; 93 : 1792-6.

e39. Kantarjian HM, O'Brien S, Cortes JE, et al.: Treatment of Philadelphia chromosome-positive, accelerated-phase chronic myelogenous leukemia with imatinib mesylate. Clin Cancer Res 2002; 8 : 2167-76

e40. Druker BJ, Sawyers CL, Kantarjian H, et al.: Activity of a specific inhibitor of the BCR-ABL tyrosine kinase in the blast crisis of chronic myeloid leukemia and acute lymphoblastic leukemia with the Philadelphia chromosome. N Engl J Med 2001; 344: 1038-42.

e41. Kantarjian HM, Cortes J, O'Brien S, et al.: Imatinib mesylate (STI571) therapy for Philadelphia chromosome-positive chronic myelogenous leukemia in blast phase. Blood 2002; 99: 3547-53

e42. Ottmann OG, Druker BJ, Sawyers CL, et al.: A phase 2 study of imatinib in patients with relapsed or refractory Philadelphia chromosome-positive acute lymphoid leukemias. Blood 2002; 100: 1965-71.

e43. Darkow T, Henk HJ, Thomas SK, et al.: Treatment interruptions and non-adherence with imatinib and associated healthcare costs: a retrospective analysis among managed care patients with chronic myelogenous leukaemia. Pharmacoeconomics 2007; 25: 481-96.

e44. Gorre ME, Mohammed M, Ellwood K, et al.: Clinical resistance to STI-571 cancer therapy caused by BCR-ABL gene mutation or amplification. Science 2001; 293: 876-80.

e45. von Bubnoff N, Schneller F, Peschel CDuyster J: BCR-ABL gene mutations in relation to clinical resistance of Philadelphiachromosome-positive leukaemia to STI571: a prospective study. Lancet 2002; 359: 487-91.

e46. Hochhaus A, Kreil S, Corbin AS, et al.: Molecular and chromosoma mechanisms of resistance to imatinib (STI571) therapy. Leukemia 2002; 16: 2190-96. e47. Branford S, Rudzki Z, Walsh S, et al.: High frequency of point mutations clustered within the adenosine triphosphate-binding region of $B C R / A B L$ in patients with chronic myeloid leukemia or Ph-positive acute lymphoblastic leukemia who develop imatinib (STI571) resistance. Blood 2002; 99: 3472-75.

e48. Roche-Lestienne C, Soenen-Cornu V, Grardel-Duflos N, et al. Several types of mutations of the Abl gene can be found in chronic myeloid leukemia patients resistant to STI571, and they can preexist to the onset of treatment. Blood 2002; 100: 1014-18.

e49. Shah NP, Nicoll JM, Nagar B, et al.: Multiple BCR-ABL kinase domain mutations confer polyclonal resistance to the tyrosine kinase inhibitor imatinib (STI571) in chronic phase and blast crisis chronic myeloid leukemia. Cancer Cell 2002; 2: 117-25.

e50. Marktel S, Marin D, Foot N, et al.: Chronic myeloid leukemia in chronic phase responding to imatinib: the occurrence of additional cytogenetic abnormalities predicts disease progression. Haematologica 2003; 88: 260-7.

e51. Cortes JE, Talpaz M, Giles F, et al.: Prognostic significance of cytogenetic clonal evolution in patients with chronic myelogenous leukemia on imatinib mesylate therapy. Blood 2003; 101 : 3794-800.

e52. Hochhaus A, La Rosee P: Imatinib therapy in chronic myelogenous leukemia: strategies to avoid and overcome resistance. Leukemia 2004; 18: 1321-31.

e53. Gambacorti-Passerini C, Barni R, le Coutre P, et al.: Role of alpha1 acid glycoprotein in the in vivo resistance of human BCRABL(+) leukemic cells to the abl inhibitor STI571. J Natl Cancer Inst 2000; 92: 1641-50.

e54. Picard S, Titier K, Etienne G, et al.: Trough imatinib plasma levels are associated with both cytogenetic and molecular responses to standard-dose imatinib in chronic myeloid leukemia. Blood 2007; 109: 3496-9.

e55. White DL, Saunders VA, Dang P, et al.: Most CML patients who have a suboptimal response to imatinib have low OCT-1 activity: higher doses of imatinib may overcome the negative impact of low OCT-1 activity. Blood 2007; 110: 4064-72.

e56. Lahaye T, Riehm B, Berger U, et al.: Response and resistance in 300 patients with BCR-ABL-positive leukemias treated with imatinib in a single center: a 4.5-year follow-up. Cancer 2005; 103 : 1659-69.

e57. von Bubnoff N, Veach DR, van der Kuip H, et al.: A cell-based screen for resistance of Bcr-Abl-positive leukemia identifies the mutation pattern for PD166326, an alternative Abl kinase inhibitor. Blood 2005; 105: 1652-9.

e58. Nicolini FE, Chabane K, Tigaud I, Michallet M, Magaud JP, Hayette S: BCR-ABL mutant kinetics in CML patients treated with dasatinib. Leuk Res 2007; 31: 865-8.

e59. Kantarjian HM, Talpaz M, O'Brien S, et al.: Dose escalation of imatinib mesylate can overcome resistance to standard-dose therapy in patients with chronic myelogenous leukemia. Blood 2003; 101: 473-5.

e60. Zonder JA, Pemberton P, Brandt H, Mohamed AN, Schiffer CA The effect of dose increase of imatinib mesylate in patients with chronic or accelerated phase chronic myelogenous leukemia with inadequate hematologic or cytogenetic response to initial treatment. Clin Cancer Res 2003; 9: 2092-7.

e61. Rea D, Etienne G, Corm S, et al.: Imatinib dose escalation for chronic phase - chronic myelogenous leukaemia patients in primary suboptimal response to imatinib $400 \mathrm{mg}$ daily standard therapy. Leukemia 2009; 23: 1193-6.

e62. Jabbour E, Kantarjian HM, Jones D, et al.: Imatinib mesylate dose escalation is associated with durable responses in patients with chronic myeloid leukemia after cytogenetic failure on standarddose imatinib therapy. Blood 2009; 113: 2154-60.

e63. Nicolini FE, Corm S, Le QH, et al.: Mutation status and clinical outcome of 89 imatinib mesylate-resistant chronic myelogenous leukemia patients: a retrospective analysis from the French intergroup of CML (Fi(phi)-LMC GROUP). Leukemia 2006; 20: 1061-6. 
e64. Press RD, Willis SG, Laudadio J, Mauro MJ, Deininger MW: Determining the rise in BCR-ABL RNA that optimally predicts a kinase domain mutation in patients with chronic myeloid leukemia on imatinib. Blood 2009; 114(13): 2598-605.

e65. Jabbour E, Jones D, Kantarjian HM, et al.: Long-term outcome of patients with chronic myeloid leukemia treated with second generation tyrosine kinase inhibitors after imatinib failure is predicted by the in vitro sensitivity of BCR-ABL kinase domain mutations. Blood 2009; 114(10): 2037-43.

e66. Shah NP, Tran C, Lee FY, Chen P, Norris D, Sawyers CL: Overriding imatinib resistance with a novel $\mathrm{ABL}$ kinase inhibitor. Science 2004; 305: 399-401.

e67. Weisberg E, Manley PW, Breitenstein W, et al.: Characterization of AMN107, a selective inhibitor of native and mutant Bcr-Abl. Cancer Cell 2005; 7: 129-41.

e68. Menzel H, von Bubnoff N, Hochhaus A, Haferlach C, Peschel C, Duyster $\mathrm{J}$ : Successful allogeneic stem cell transplantation in second chronic-phase CML induced by the tyrosine kinase inhibitor nilotinib (AMN107) after blast crisis under imatinib. Bone Marrow Transplant 2007; 40: 83-84.

e69. Ottmann 0, Dombret H, Martinelli G, et al.: Dasatinib induces rapid hematologic and cytogenetic responses in adult patients with Philadelphia chromosome positive acute lymphoblastic leukemia with resistance or intolerance to imatinib: interim results of a phase 2 study. Blood 2007; 110: 2309-15.

e70. Talpaz M, Shah NP, Kantarijan H, et al.: Dasatinib in imatinib-resistant Philadelphia chromosome-positive leukemias. N Engl J Med 2006; 354: 2531-41.

e71. Kantarijan H, Giles F, Wunderle L, et al.: Nilotinib in imatinib-resistant CML and Philadelphia chromosome-positive ALL. N Engl J Med 2006; 354: 2542-51.

e72. Kantariian H, Pasquini R, Levy V, et al.: Dasatinib or high-dose imatinib for chronic-phase chronic myeloid leukemia resistant to imatinib at a dose of 400 to 600 milligrams daily: two-year follow-up of a randomized phase 2 study (START-R). Cancer 2009; 115(18): 4136-47.

e73. Kantarijan H, Cortes J, Kim DW, et al.: Phase III study of dasatinib $140 \mathrm{mg}$ once daily versus $70 \mathrm{mg}$ twice daily in patients with chronic myeloid leukemia in accelerated phase resistant or intolerant to imatinib: 15-month median follow-up. Blood 2009; 113: 6322-29. 